\title{
Integrating Safety and Quality Into the Requirements Oriented Product Development by the Example of a New Electro Mobility Concept
}

\author{
Nadine Schlüter ${ }^{1 *}$, Petra Winzer ${ }^{2}$, Marén Willing ${ }^{3}$ \\ 1,2,3 Research Group Product Safety and Quality, University of Wuppertal, Gaußstraße 20, 42119 Wuppertal, Germany
}

\section{BIOGRAPHICAL NOTES}

Nadine Schlüter received the degree in logistics at University of Dortmund, Dortmund, Germany, in 2006 and the Ph.D. degree (magna cum laude) from the University of Wuppertal, Wuppertal, Germany, in 2012. She worked on many projects in the areas of customer satisfaction, requirement management and quality engineering. Dr. Schlüter is assistant chief in the Ruhr-Area group of the German Society for Quality (DGQ) since 2012.

Petra Winzer obtained her Ph.D. degree from the Technical University of Dresden, Dresden, Germany, and her habilitation from the Technical University of Berlin, Germany, in 1996. Until her appointment as Chair for Product Safety and Quality at the University of Wuppertal in 1999, she held various positions at the Brandenburg Technical University in Cottbus. Her current research fields are systems engineering, management systems, quality and sustainable development management. Dr. Winzer has been a member of German Academy of Science and Engineering (acatec) since 2007 and prorector for transfer and internationality at the University of Wuppertal since 2008.

Marén Willing studied Safety Engineering and Quality Engineering at the University of Wuppertal where she received her B.Sc. degree in 2011 and M.Sc. degree in 2013. After having worked on different research projects during her studies since 2009, she joined the Research Group "Product Safety and Quality Engineering" as a scientific employee and doctoral student in 2013. She is responsible for system modeling and reliability engineering within the transnational project K-VEC.

\section{KEY WORDS}

Generic Systems Engineering; integrated and requirements-oriented product development.

\footnotetext{
ABSTRACT

Modern product development is characterized by an increasing variety of requirements challenging the designing engineers. Neither current approaches of requirements engineering nor approaches from the field of systems engineering are satisfactory to manage these requirements for complex products. Against this background, the present paper introduces a holistic Generic Systems Engineering approach (GSE), which allows the combined consideration of requirements from various specialist disciplines along the product life cycle. Thereby the basis is created to apply a workflow of methods for risk analysis. A new electro mobility concept exemplifies GSE.
} 


\section{Introduction}

The increasing variety of requirements concerning technical products challenges the designing engineers $[1,2]$. As this variety is barely manageable, it is a common reason for recall campaigns. One, but not the only evidence is the situation of Airbus [3]. Furthermore have battery problems led to a grounding of boeings dreamliner, recalls in automotive industry are nothing exceptional and the delivery of trains manufactured by Siemens has been delayed. Examples like these appear in the news almost daily $[4,5]$. Neither the requirements engineering $[6,7,8,9,10]$, nor recent approaches for product development relying on systems engineering $[11,12]$ may solve these problems with a long-term perspective. One of the main reasons is the separated consideration of requirements concerning different aspects, such as:

\section{- safety requirments, \\ - quality requirements, \\ - environmental requirements, \\ - aesthetic requirements, as well as \\ - financial requirements.}

Hence, isolated components are disregarded, interactions overseen and contradictions do not attract attention. If the result is, that requirements are not fulfilled or not satisfyingly fulfilled, may the consequences be fatal, particularly concerning safety and quality requirements. Aggravating this situation the term 'requirements' is not defined consistently in different standards although they broach the same issue. Equally 'safety', 'reliability', 'quality' and 'risk' to mention just a few, are not defined consistently [13]. Even though quality is defined as "degree to which a set of inherent characteristics fulfils requirements" according to EN ISO 9000 [14] are more definitions of quality to be found in technical literature [15-18]. A sharp differentiation between safety and quality is not recommendable because of the varying definitions. This subdivision should be neglected to focus on the significance of both sets of requirements and their interactions, as the requirements-oriented product development claims. This approach is based on systems thinking [19], which implies defining the system under consideration via black-box approach as well as investigating, systematizing, evaluating and weighting the requirements [20]. Based upon this system definition it is clearly determined what the system has to provide, so the product development process may be performed targetoriented. Within the theoretical approach below is described, how the system definition is integrated in the product development process and how this process is executed. Subsequent to the theoretical description, this approach adopted to an example from the field of electromobility. Eventually, the results are summarized and discussed.

\section{Theoretical Approach Generic Systems Engineering (GSE)}

Applying systems engineering, complex system structures can be dissembled based on simple rules and be depicted systematically. It is a structured and interdisciplinary approach [21, 22], which is characterized by one disadvantage. During the development over time, it was splitted into numerous subject-specific systems engineering approaches, as Figure 1 evidences.

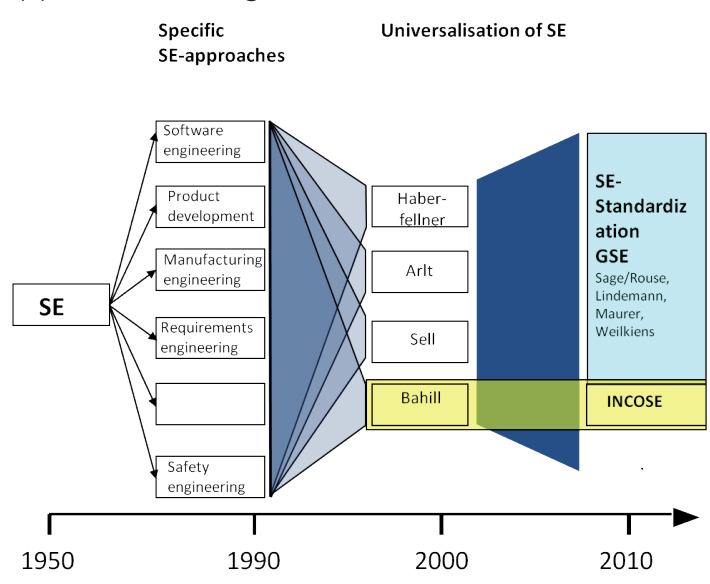

Fig. 1: Development of Systems Engineering (based on [23])

Haberfellner, Lindemann and Weilkins as well as Sage and Rouse strive to combine these various approaches for problem solution within the systems engineering to one general conceptual approach [22, 24 - 26]. Each of these authors claims to promote a conceptual approach of general relevance. In fact, the user still has to choose between different concepts instead of receiving a recommendation for only one conceptual approach. Additionally, the regarded system is only at the beginning in the limelight of the problem solving, a continuous interaction between the SEthought framework and SE-conceptual approach is not maintained. Defining the system right at the 
beginning of problem solving, developing a mutual system model as well as continuous specification are indispensable for problem solving for the reason of enabling interdisciplinary teams to deal with current problems of product development [26]. Based on this demand as well as the systems thinking and the development of a standardized thought framework, which is associated with the conceptual approach, the Generic Systems Engineering approach (GSE-approach) was established [27]. GSE is an universal approach for problem solving, which contains the development of a consistent and standardized system model. Using this system model, problems may be recognized, analyzed and processed independently from specialist disciplines. The integral parts of this approach, the GSE-conceptual approach and the GSE-thought framework, are depicted in Figure 2

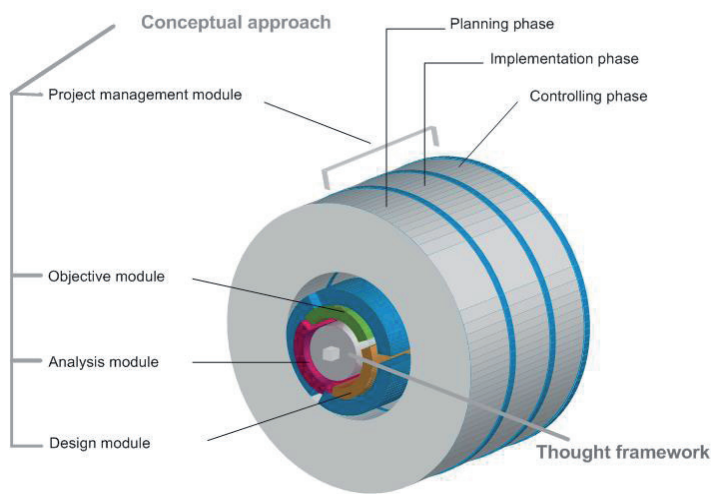

Fig. 2: The Generic Systems Engineering approach (GSE approach) [27]

As the thought framework is based on systems thinking, it allows standardized modeling of products, which is indispensable for the detection of problems. In contrast to other systems engineering approaches, the GSE-approach implies a consistent and standardized system model. Every problem is assigned to a precisely defined system, which is represented using a set number of views on the system. Hereupon the problem solving is established by adjusting and specifying the developed model. Consequently, a strong interaction between thought framework and conceptual approach is essential. The term conceptual approach was chosen over conceptual model, as Lindemann and Haberfellner recommend [12, 22].

In accordance with the GSE-conceptual ap- proach, problem solving consists of four modules: GSE-analysis module, GSE-objective module, GSEdesign module and project management module. Analysis, objective and design module are part of the problem solving, whereas the project management module organizes the other modules during the phases of planning, implementation and controlling. All modules exploit problem specific methods and procedures [28]. Results that have been achieved applying the conceptual approach need to be documented in the GSE thought framework. Hence, the thought framework of the analyzed product is specified with documented adaptations during the problem solving process. GSE-thought framework as well as GSE-conceptual base on principals of systematic thinking and acting. They apply these principles adjusted to the specific problem. [27]

Appliance the GSE-conceptual approach requires various stages of processes. Each one of the stages contains the four modules of the conceptual approach. The stages, described more in detail in the following, are:

- definition of the product development process,

- definition of the product system,

- system depiction and conceptual approach,

- requirements investigation and ranking,

- alignment between requirements and product,

- design adaptations.

\section{Definition of the product development process}

In the first stage it is determined, which phase of the product development process the respective product has been achieved yet. Figure 3 provides a general product development process that facilitates investigating the phase of the individual product.

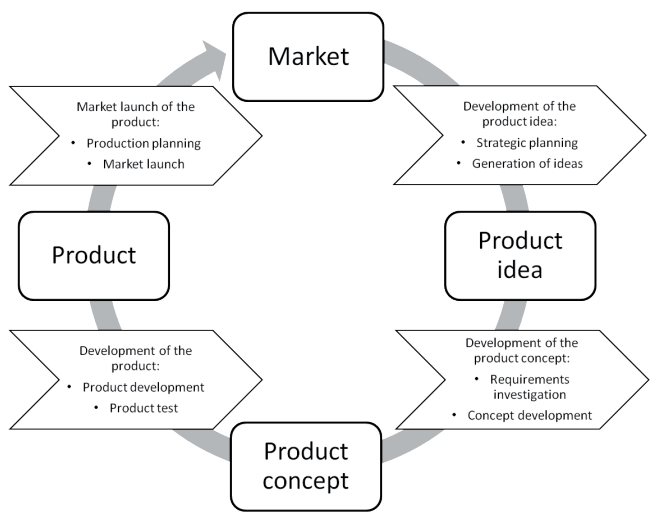

Fig. 3: General sequence of a product development process [29] 
Within every phase needs to be checked whether the requirements, expressed in advance, are fulfilled or not, no matter if they target safety or quality aspects. The application of methods and procedures is necessary, but especially in design and construction rarely realized [24, 30, 31]. As a result, it is hardly possible to determine the degree of requirement fulfillment within the early phases of product development. Combinations of methods and procedures are usually not sought and applied, even though the output of one method could potentially be input for another method [27]. Besides that, no structured input is available for the methods as they do not use an identical depiction of the respective product [32]. That is why sometimes results are achieved, which are not comprehensible for third parties. Thus, one standardized product system, clearly distinguished from its environment, is required.

\section{Definition of the product system}

Specifying a product system during the product development process requires some fundamental predefinitions. Such as: What is the product system? What is part/not a part of the product system? What is the product system supposed to do? These predefinitions are made within the third stage. In addition to a definition of boundaries between the system and its environment, the black-box approach is recommendable. It includes disregarding the internal structure and focusing on purpose as well as input and output of the system [20]. Hence the effect of the product system on its environment is depicted.

\section{System depiction and conceptual approach}

Subsequent to the definition of the product system, the specification of the defined system is performed. Figure 2 summarizes the recommended procedure. Level $A$ is the black-box established in the former stage. Level B 'opens' this black-box by identifying the subsystems and describing them as black-boxes in the same way. By applying this approach repeatedly, the resulting model becomes more and more detailed.

Using the black-box approach for system definition and specification corresponds to the principles of systems engineering, which supports systematical problem identification and solving. Additionally, the system depiction applies the Demand Compliant Design (DeCoDe), which involves the description of a system from four points of view: requirements, functions, processes and components [28]. Elements of these views are defined in this stage, therefore basic system model is developed.

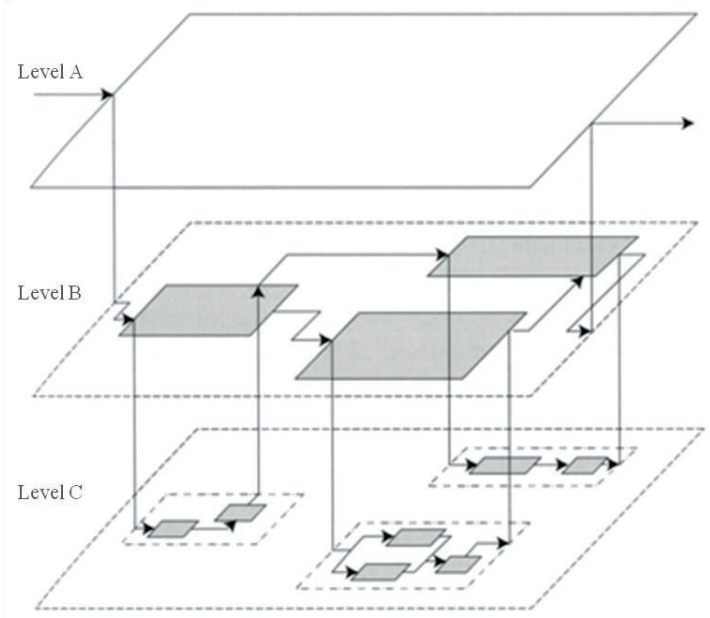

Fig. 4: Successive specification of a system by [22]

\section{Requirements investigation and ranking}

The basic system model already contains a first listing of the requirements known in this early stage of product development. Achieving the objective of requirements-oriented product development requires more than that. Extensive research of safety, quality, ecological and economical requirements needs to be done. Subsequent to the investigation, the requirements have to be structured and rated [33] in order to recognize contradicting requirements for being able to find a solution.

\section{Alignment between requirements and product}

An alignment between the requirements listed in the basic model and the structured and rated requirements from the former stage discloses the gap between already realized and unconsidered requirements. This gap represents the need for system improvements.

\section{Design adaptations}

The specification of the system model progresses during the design process, as elements are added to the model or adapted to changed circumstances. Relations between those elements are adequate for the depiction of interdependencies inherent to the system.

Based on the requirements, functions can be devised, which define the purpose of a system re- 
spectively subsystem in a solution-neutral manner. Thus, the function attaches a target to the transformation from input to output, the system causes. How this transformation occurs, is content of the process-view. Processes realize functions by utilizing components that are the fourth DeCoDe-view. Components represent the physical parts of the system [34]. With this DeCoDe-method, the blackboxes from the stage of system depiction and conceptual approach are filled with models, creating a depiction of the whole product system and relating requirements to the product. Need for optimization occurring during the specification process can be accomplished, resulting in a high degree of requirements fulfillment.

\section{Summary}

The result of the six described stages is a product model, which represents the current stage of development at any time. Therefore a better comprehension of the system is supported, problem solution and further development are facilitated by making need for optimization visible. To sum up, requirements-oriented product development can be achieved by means of the Generic Systems Engineering approach.

A system from the field of electro mobility exemplifies the presented approach in the following.

\section{Application and Discussion 3.1 Example of application}

The application of the GSE-approach to the K-Vec project aims to develop proposals for the improvement of technology and infrastructure. Main focus lies on the question, how emission-free mobility could be realized using ultracapacitors in vehicles that are used in not rail-borne local public transport, but follow a predictable route. Though the usage of batteries has been researched intensively during the last years, decisive disadvantages could not be removed. These disadvantages include costs, range, operating life, weight and failure proneness (quality aspects) [35], which have caused the insufficient spread of purely electronically driven vehicles on the european market. The other side of the medal are socially relevant advantages regarding ecology like the sustainability in the use of regenerative energies as well as minimizing emissions. For pushing the dissemination of electric vehicles forward are new concepts in the development. These are, beside $\mathrm{K}$-Vec, approaches like the H2-
Hybridbus-System by VKD [36], the PRIMOVE developed by Bombardier [37] or the Credo E-Bone Concept [38] and trolleybus systems bound to contact wires [39]. Especially for vehicles deployed in public transport, which require a certain infrastructure, these technologies seem to be promising. Focused is not the pure substitution of conventional drives by electric drives, but the development of an overall concept, which includes the use and storage of electric energy as well the energy-supply. Striving towards an innovative and holistic concept implies the chance of integrating efficiency, performance improvement and safety from the beginning on. Main objective of the K-VEC project is the development and testing of systems and components for the energy-supply and the fast energy transfer. These systems and components should allow to insert ultracapacitors as a primarily energy storage in a vehicle and to correspond thereby to the high demands regard to the security, reliability, quality, efficiency and economy. Ultracapacitors, in short term named ultracaps, are robust modern energy storage media, which have not established themselves on the market for motor vehicles so far, due to low energy density and high costs in comparison to batteries [49]. Nevertheless, ultracapacitors combine two basic advantages towards accumulators. On the one hand, they have a high lifetime of up to one million charging cycles without significant efficiency losses, on the other hand, they are characterized by fast energy in- and output. Therefrom, ultracapacitors are capable to provide high amounts of energy during short time and may equally quickly be recharged [40]. This usage profile transferred to electrochemical accumulators would result in a striking shortened lifetime or make their manual mounting and dismounting necessary. The economy of time concerning the energy transfer of ultracapacitors, combined with decentralized charging stations, is the key to success within the K-VEC project, which is funded by the Costs and weight is reduced by restricting the amount of energy carried on the vehicle to the energy necessary to reach the next stop, taking into account the possibility of being forced to skip one stop and an emergency reserve. Charging takes place at decentralized charging stations integrated in bus stops, which are distributed alongside the routes for public transport and designed resistant towards rough weather and vandalism. 
The ideal field of application for this technology is not rail-borne public transport, as the advantages of the holistic systems thinking can exploited to the maximum. Hence, busses shall be equipped with a combination of ultracaps and batteries (presumably lithium-ion batteries), which absorb enough energy through charging carpets at the bus stops to reach the next bus stop. The batteries serve energy buffer and extension of the range. As the residence time at the bus stop is not long enough to charge a lithium-ion battery, the battery is charged on the road taking energy from the ultracaps. A continuous charging process is performed, which equals the technical conditions conventional accumulators usually are faced with. Thus, the combination of both technologies supplements each other. Main challenge for future-oriented transport solutions is the supply of energy. While rail vehicles typically obtain energy from an external infrastructure, do motor vehicles store energy on-board. On-board saving of energy is associated with risks, especially in case of an accident. It must be excluded, that body-parts become currentcarrying. Another potential risk is the charging process. Safe operation must be granted during the process, which implies positioning accuracy of the plug, energy management of the batteries as well as ultracaps, etc. Additionally, the charging carpets integrated in the road surface must not endanger other individuals, including persons in vehicles in contact with the charging carpet or individuals in direct contact, for instance walking over the carpet wearing metal covered boots. Protection against vandalism has to be concerned as well as guaranteeing functionality during winter, which comes with snow, ice and road salt. Precipitation, extreme temperatures and foreign object on the charging carpet or the road surface have to be considered. Ensuring the reliability of the K-Vec system under any environmental condition requires further investigation improvements on the system.

Beside the field of reliability, functional safety and protection of third parties, quality aspects like short charging times, life span of the batteries, fast energy transfer, etc. need to be considered. The energy stored on-board of the vehicles must at no time endanger passengers or the rescue team. Fire development caused by deficient cooling of the batteries after a crash-test was observed under laboratory conditions and represents a high sec- ondary risk [41] that has to be considered within the system analysis. Operating errors as well as vandalism must remain effectless. In terms of these requirements the charging concept $\mathrm{K}$-Vec system involves clear benefits. On the one hand, the amount of energy carried on-board of the vehicle is restricted to a minimum, on the other hand, only a small section of the charging carpet becomes current-carrying and only under the condition of a successful WiFi-identification.

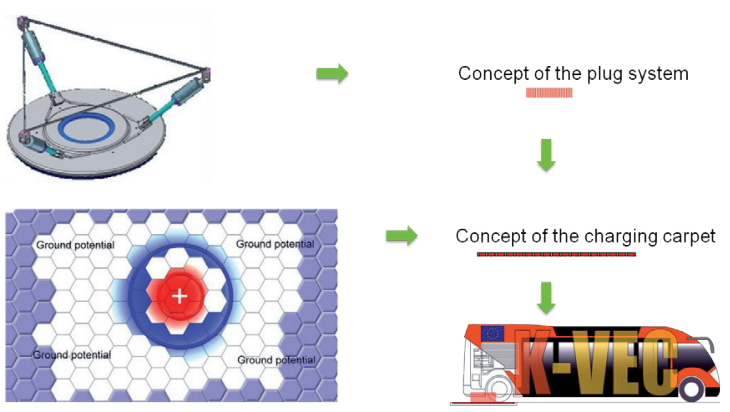

Fig. 5: The K-Vec System

\subsection{Application of GSE}

How can GSE support the integration of these various requirements into the requirements-oriented product development process of the K-Vec system?

First step is the precise definition of system boundaries for the system, which includes interaction between immovable parts and vehicle (cf. Figure 6).

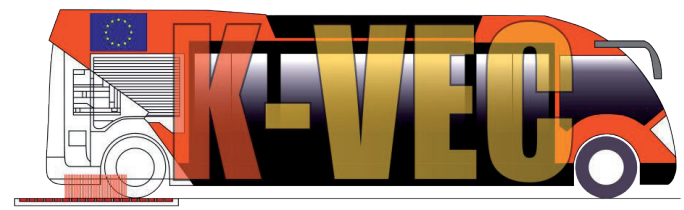

Fig. 6: Interaction between immovable parts and K-Vec vehicle

Subsequently, the GSE-approach suggests the establishment of a thought framework, which exploits DeCoDe. DeCoDe is the abbreviation for Demand Compliant Design [42], a method for system modeling based on four standardized views and the interrelations between them. Therefore, K-Vec is depicted using the views of requirements, functions, processes and components (cf. Figure 7).

Since the necessary conditions were created, the target-oriented analysis of the product concept may be initiated. Analysis methods for safety, ecological, 
and economical aspects need to be chosen and applied. The application of methods from the field of quality science is recommendable, as the degree of requirements-fulfillment is rated. For avoidance of nonconformity, the case of non-fulfillment, methods like FMEA (Failure Mode and Effects Analysis) and FTA (Fault Tree Analysis) should be employed. Thereby the requirements-fulfillment of the system is investigated not making a difference between safety, quality and ecological aspects, as all of them are summarized under the term 'requirements'.

Nevertheless, within the project K-Vec special focus for the research group product safety and quality engineering lies on reliability aspects. Sev- eral analysis methods (Fault Tree Analysis, Reliability Block Diagrams, Failure Mode, Effects and Criticality Analysis and Mean Time Between Failure) are applied utilizing the system model perfectly. As the system model provides essential input data and subsumes the results of the methods, synergy effects are created. In addition to the profit of being able to deduce measures for failure prevention on basis of the reliability analysis, the integration of the results into the system model supports the anticipation of failure effects and changes on the system. This cycle, summarized in Figure 8, allows a targetoriented redesign adapted to the particular requirements.

\section{System-oriented approach:}

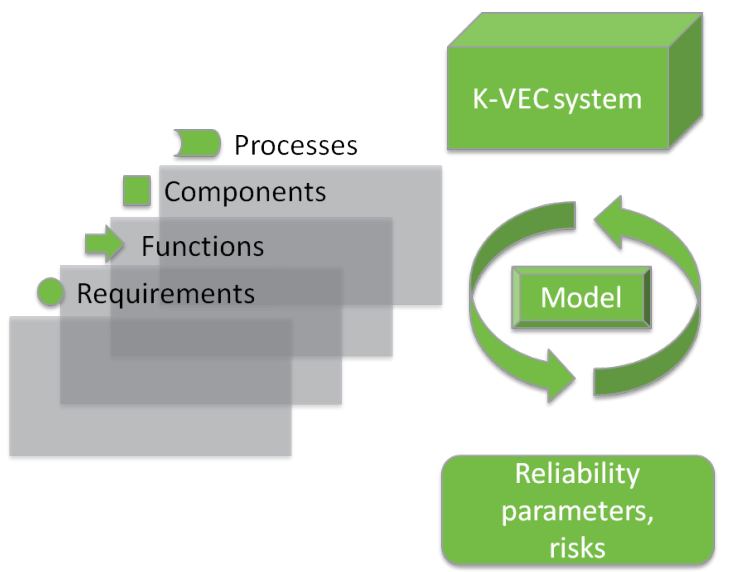

- Depiction of the K-VEC system

- Modeling of the K-VEC bus

- Modeling of the charging carpet

- Reliability analysis using the workflow of methods including

- RBD

- FTA

- FMECA

- MTBF

- Evaluation and minimization of risks

- Identifying critical components and processes

- Recommend measures for failure prevention

Fig. 7: System-oriented approach for a requirement-compliant design of the K-Vec system

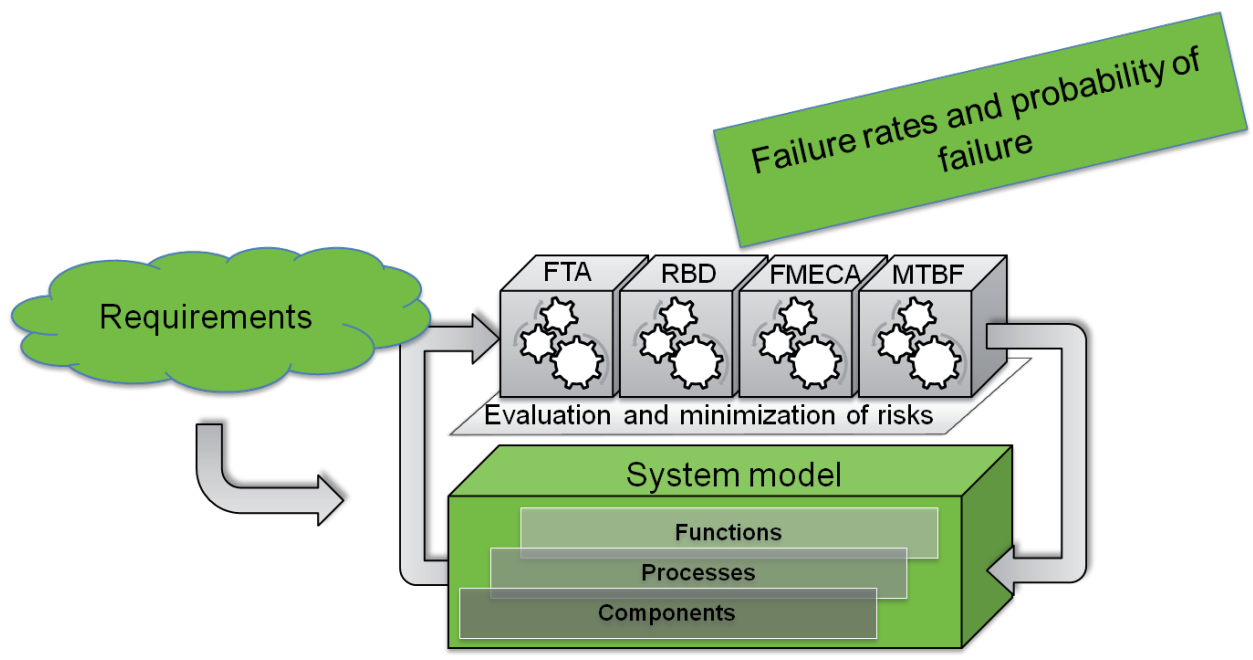

Fig. 8: System-oriented approach for a requirement-compliant design of the K-Vec system 


\section{Conclusions}

Applying the GSE-approach to K-Vec demonstrated how safety, quality, ecological and economical requirements should be integrated to the requirements-oriented product development efficiently and systematically. The degree of requirement-fulfillment can be tested by making use of common and well-chosen methods. Using those methods from the field of quality science for a better product development in general potentially increases the efficiency of the development process, as they ensure the consideration of safety and reliability requirements additionally.

\section{Acknowledge}

The project "K-Vec" is sponsored by the German government via the Federal Ministry of Economics and Technology, project-no. 01MX12020.

\section{References}

[1] Badke-Schaub, P.; Frankenberger, E. (2004 [publ. 2003]). Management kritischer Situationen. Produktentwicklung erfolgreich gestalten. Springer, Berlin [u.a.].

[2] Gausemeier, J. (2007). Strategisches Produktionsmanagement. Hanser, München.

[3] Sächsische Zeitung (2012). Flugbehörde holt Riesenflieger vom Himmel. Newspaper from 9.02.2012.

[4] Hamburg Abendblatt (2012). Siemens kann ICE nicht liefern - Bahn bangt um Fahrplan. from http://www.abendblatt. de/wirtschaft/article111419695/Siemens-kann-ICE-nichtliefern-Bahn-bangt-um-Fahrplan.html, 23.11.2012.

[5] Die Welt (2012). BMW hat drei Mal so viele Rückrufe wie Verkäufe, from http://www.welt.de/wirtschaft/article108242441/BMW-hat-drei-Mal-so-viele-Rueckrufe-wieVerkaeufe.html, 16.03.2013.

[6] Danner, S. (1996). Ganzheitliches Anforderungsmanagement für marktorientierte Entwicklungsprozesse. Hanser, München, Wien.

[7] Davis, A.M.; Hickey, A.M.; Zweig, A.S. (2007). Requirements Management in a Project Management Context. In: Morris, P.W.G.; Pinto, J.K. (Ed.). The Wiley Guide to Project Technology, Supply Chain, and Procurement Management. John Wiley \& Sons, Inc., Hoboken, N.J.. Pp. 1-31.

[8] Rupp, C. (2002). Requirements- Engineering und - Management; Professionelle, iterative Anforderungsanalyse für die Praxis. Hanser.

[9] Pohl, K. (2008). Requirements Engineering; Grundlagen, Prinzipien, Techniken. Dpunkt-Verl., Heidelberg.

[10] Schlund, S. (2011) Anforderungsaktualisierung in der Produktentwicklung; Entwicklung einer Methodik zur Aktu- alisierung von Anforderungen durch die Einbindung anforderungsrelevanter Ereignisse. Shaker, Aachen.

[11] Gausemeier, J.; Plass, C.; Wenzelmann, C. (Ed.) (2009). Zukunftsorientierte Unternehmensgestaltung; Strategien, Geschäftsprozesse und IT-Systeme für die Produktion von morgen. Hanser, München, Wien.

[12] Lindemann, U. (2005). Methodische Entwicklung technischer Produkte; Methoden flexibel und situationsgerecht anwenden. Springer, Berlin

[13] Winzer, P.; Schnieder, E.; Bach, F.-W. (ed.) (2010). Sicherheitsforschung-Chancen und Perspektiven. acatech - Deutsche Akademie der Technikwissenschaften, Springer Verlag, Berlin, Heidelberg.

[14] DIN EN ISO 9001:2008-12, (2008). Quality management systems - Requirements, Beuth, Berlin

[15] Kamiske, G.F.; Brauer, J.-P. (2005). Qualitätsmanagement von A bis Z. Erläuterungen moderner Begriffe des Qualitätsmanagements. 5. Auflage. Carl Hanser, München.

[16] Pfeifer, T. (2001). Praxisbuch Qualitätsmanagement. Aufgaben, Lösungswege, Ergebnisse. 2. Auflage. Hanser, München.

[17] Garvin, D.A. (1984). What Does „Product Quality” Really Mean?. Sloan Management Review. p. 25-45.

[18] Crosby, P.B. (1979). Quality is free: the art of making quality certain. McGraw-Hill, New York.

[19] Sitte, J.; Winzer, P. (2011). Demand Compliant Design. IEEE Transactions on Systems, Man and Cybernetics-Part A: Systems and Humans, (Volume 41, No. 3).

[20] Haberfellner, R.; Daenzer, W.F. (1999). Systems Engineering; Methodik und Praxis. Verl. Industrielle Organisation, Zürich.

[21] Weilkiens, T. (2007). Systems engineering with SysML; Modeling, analysis, design. Morgan Kaufmann OMG Press/Elsevier, Amsterdam

[22] Haberfellner, R.; Vössner, S.; Weck, O.; Fricke, E. (2012). Systems Engineering. Grundlagen und Anwendung. Orell Füssli, Zürich.

[23] Sitte, J.; Winzer, P. (2011). Systemmodellierung im Fokus von Generic Systems Engineering. In: Gesellschaft für Systems Engineering e.V. (Ed.) Tag des Systems Engineering, Berlin.

[24] Weilkiens, T. (2007). Systems engineering with SysML; Modeling, analysis, design. Morgan Kaufmann OMG Press/Elsevier, Amsterdam.

[25] Sage, A.P.; Rouse, W.B. (Ed.) (2009). Handbook of systems engineering and management. John Wiley \& Sons, Hoboken, NJ.

[26] Sitte, J.; Winzer, P. (2006). Evaluation of a new complex system design method on a mechatronic automotive product. In: Dória MTdC (Ed.) 2006 International Engineering Management Conference, pp. 278-282.

[27] Winzer, P. (2012). Das Generic Systems Engineering; - ein 
methodischer Ansatz zur Komplexitätsbewältigung. In: Winzer P (Hrsg). Generic Systems Engineering als Basis für die Weiterentwicklung des WGMK-Modells. Shaker, Aachen, pp. 1-19.

[28] Sitte, J., Winzer, P. (2011). Demand Compliant Design. In: IEEE Transactions on Systems, Man, and Cybernetics-Part A: Systems and Humans, Volume 41, No. 3.

[29] Huber, M.; Schlüter, N. (2013). Ansatz der Kundenintegration durch Nutzung der Virtuellen Realität in den frühen Phasen des Produktentwicklungsprozesses. In: Petra Winzer (Hrsg.). Prozessoptimierung in Unternehmen und Unternehmensnetzwerken. Reihe: Berichte zum Generic-Management. Shaker Verlag, Aachen, pp. 63-80.

[30] Schlund, S.; Riekhof, F.; Winzer, P. (2009). Probleme bei der Entwicklung mechatronischer Systeme - Ergebnisse einer Industriebefragung. In: ZWF - Zeitschrift für wirtschaftlichen Fabrikbetrieb. Ausgabe 01-02/2009. Carl Hanser Verlag, pp. 54-59.

[31] Ott, S.; Sitte, J.; Winzer, P. (2006). Nutzungsmöglichkeiten des Requirement Engineering zum Design von komplexen Systemen. In: Petra Winzer (Hrsg.). Generic-Management und Möglichkeiten der Stakeholderintegration. Band 2006,1. Shaker Verlag, Aachen, pp. 47-60.

[32] Ott, S. (2009). Konzept zur methodischen System-Modellierung in der anforderungsgerechten Produktentwicklung. Shaker, Aachen.

[33] Schlund, S.; Winzer, P. (2010). DeCoDe-Modelle zur anforderungsgerechten Produktentwicklung. In: Gerhard Bandow (Hg.): "Das ist gar kein Modell!". Unterschiedliche Modelle und Modellierungen in Betriebswirtschaftslehre und Ingenieurwissenschaften. 1. Aufl., Gabler, Wiesbaden. p. $277-$ 293.

[34] Mamrot, Michel; Marchlewitz, Stefan; Nicklas, Jan-Peter; Riekhof, Florian; Schlüter, Nadine; Seider, Gabriele; Winzer, Petra (2012). Begriffe im Kontext des Generic Systems Engineering - Ansatzes. In: Petra Winzer (Hg.): Generic Systems Engineering als Basis für die Weiterentwicklung des WGMKModells, 2/12. Shaker, Aachen. p. 21-30.

[35] Musk, Elon; Ghosn, Carlos (2012). Spannungseinbruch. In: WirtschaftsWoche (047). From http:// www.wiso-net.de/webcgi?START=A60\&DOKV_ $\mathrm{DB}=\mathrm{ZGEN} \& D O K V \_N O=W W D D 687595-64 B B-482 \mathrm{D}-80 D D$ 5372B8C4COD0\&DOKV_HS=0\&PP $=1$.

[36] vossloh KIEPE, H2 hybrid bus, from http://www.vossloh-kiepe.com/electric-buses/hybrid-buses/h2-hybridbus?set_language=en, 16.03.2013.

[37] BOMBARDIER, Bombardier E-mobility Solutions Redefine Urban Transport, from http://de.bombardier.com/en/ press_release_20120919.htm, 16.03.2013.

[38] autobloggreen, Credo E-Bone concept bus utilizes fuel cell technology, from http://green.autoblog.com/2010/10/12/ credo-e-bone-concept-bus-utilizes-fuel-cell-technology-liion-b/, 16.03.2013.

[39] Trolley, Promoting electric public transport, from http:// www.trolley-project.eu/, 16.03.2013.

[40] Fraunhofer IAO (2011). Strukturstudie BWe mobil 2011 Baden-Württemberg auf dem Weg in die Elektromobilität. Stuttgart. From http://wiki.iao.fraunhofer.de/index.php/ Strukturstudie_BWe_mobil_2011

[41] Heinemann, D. (2007). Strukturen von Batterie- und Energiemanagementsystemen mit Bleibatterien und Ultracaps. Doctoral thesis, TU Berlin

[42] Hartmann, C.; Winzer, P. (2011). DeCoDe + X in KitVes. Using the Demand Compliant Design in the Development of a Solution for Harvesting High-Altitude Winds for Energy Generation on Vessels. QMOD 2011, 31.09.2011. 